\title{
Polycrystalline thin films of antimony selenide via chemical bath deposition and post deposition treatments
}

\author{
Y. Rodríguez-Lazcano, Yolanda Peña, M.T.S. Nair*, P.K. Nair \\ Department of Solar Energy Materials, Centro de Investigación en Energía, Universidad Nacional Autónoma de México, Temixco, Morelos-62580, México
}

Received 31 December 2004; received in revised form 8 July 2005; accepted 18 July 2005

Available online 18 August 2005

\begin{abstract}
We report a method for obtaining thin films of polycrystalline antimony selenide via chemical bath deposition followed by heating the thin films at $573 \mathrm{~K}$ in selenium vapor. The thin films deposited from chemical baths containing one or more soluble complexes of antimony, and selenosulfate initially did not show X-ray diffraction (XRD) patterns corresponding to crystalline antimony selenide. Composition of the films, studied by energy dispersive X-ray analyses indicated selenium deficiency. Heating these films in presence of selenium vapor at $573 \mathrm{~K}$ under nitrogen (2000 mTorr) resulted in an enrichment of Se in the films. XRD peaks of such films matched $\mathrm{Sb}_{2} \mathrm{Se}_{3}$. Evaluation of band gap from optical spectra of such films shows absorption due to indirect transition occurring in the range of $1-1.2 \mathrm{eV}$. The films are photosensitive, with dark conductivity of about $2 \times 10^{-8}(\Omega \mathrm{cm})^{-1}$ and photoconductivity, about $10^{-6}(\Omega \mathrm{cm})^{-1}$ under tungsten halogen lamp illumination with intensity of $700 \mathrm{~W} \mathrm{~m}^{-2}$. An estimate for the mobility life time product for the film is $4 \times 10^{-9} \mathrm{~cm}^{2} \mathrm{~V}^{-1}$.

(C) 2005 Elsevier B.V. All rights reserved.
\end{abstract}

PACS: $68.55 . \mathrm{Nq}$

Keywords: X-ray diffraction; Chemical deposition; Antimony selenide; Photoconductivity

\section{Introduction}

Antimony(III) selenide has a ribbon-like polymeric structure in which each $\mathrm{Sb}$-atom and each Se-atom is bound to three atoms of the opposite kind that are then held together in the crystal (orthorhombic, $a=11.62 \AA, b=11.77$ $\AA, \mathrm{c}=3.962 \AA$ ) by weak secondary bonds [1]. Optical band gaps due to both direct and indirect transitions in the range of 1 to $1.13 \mathrm{eV}$ and thermal energy gap of $1-1.32 \mathrm{eV}$ are reported for the material $[1,2]$. This makes it suitable for use as an absorber material in polycrystalline thin film solar cells [3]. A photoelectrochemical solar cell, employing antimony selenide thin film as photoanode, has shown short-circuit current of $\sim 0.45 \mathrm{~mA} / \mathrm{cm}^{2}$ and open circuit voltage of $\sim 0.37 \mathrm{~V}[4]$.

\footnotetext{
* Corresponding author. Tel.: +52 55 56229731; fax: +52 5556229742 E-mail address: mtsn@cie.unam.mx (M.T.S. Nair).
}

Polycrystalline thin films of the material have been prepared by vacuum evaporation [5], spray pyrolysis [6] and electrodeposition [7] methods, but the films obtained by chemical bath deposition are reported as amorphous [2,8]. In general, the films of $\mathrm{V}_{2} \mathrm{VI}_{3}$ compounds obtained by chemical bath method are amorphous, showing high resistivity $\left(\sim 10^{8} \Omega \mathrm{cm}\right)$ and optical band gaps that are larger than those reported for the material in the bulk [9]. Quantum confinement effect arising from the small grain size in thin film semiconductors $[9,10]$ is considered as the cause for the latter. Heating the films has been found to enhance crystallinity, thus permitting structural characterization of the material by X-ray diffraction (XRD) [9]. In this paper we report that thin films obtained from chemical baths of soluble tartrato-, citrato- or thiosulfato-complexes of antimony and sodium selenosulfate are constituted by antimony oxide in addition to antimony selenide, but the former could be converted to crystalline $\mathrm{Sb}_{2} \mathrm{Se}_{3}$ when heated at $573 \mathrm{~K}$ in presence of Se-vapor. The structural, optical and electrical properties of the films are reported. 


\section{Experimental details}

\subsection{Materials employed}

Antimony trichloride, $\mathrm{SbCl}_{3}$, and aqueous ammonia, $\mathrm{NH}_{3}(\mathrm{aq}),(30 \%)$ of Fermont chemicals, selenium powder of Alfa chemicals, and potassium antimony tartrate, triethanolamine, sodium citrate, and sodium thiosulfate of Baker Analyzed Reagents were utilized in the preparation of the chemical baths. Corning microscope glass slides of $1 \mathrm{~mm}$ thickness were used as substrates. These were cleaned well using detergent solution and water and dried prior to their use as substrates.

\subsection{Deposition of thin films}

Antimony(III) chloride does not dissolve in water, instead, precipitates as oxochloride, $\mathrm{SbOCl}$. Clear solutions are formed in high concentrations of acids or alkalis, which when diluted precipitate oxosalts or hydroxide, respectively. The presence of strong ligands such as tartrate that form soluble complexes prevents the precipitation of basic salts in aqueous solutions. In the present study, we have used one or more of the ligands-citrate, triethanolamine and thiosulfate-to form soluble complexes of antimony in the deposition bath using $\mathrm{SbCl}_{3}$ as the starting material. The other starting material, potassium antimony tartrate, is a soluble complex tartratoantimonate(III), $\left[\mathrm{Sb}_{2}\left(\mathrm{C}_{4} \mathrm{O}_{6} \mathrm{H}_{2}\right)_{2}\right]^{2-}$. The dissociation equilibria involving these complexes produce antimony(III) (aq) ions in the bath. Sodium selenosulfate was used as a source of selenide. This was prepared in the laboratory by refluxing $4 \mathrm{~g}$ of selenium powder and $12.5 \mathrm{~g}$ of sodium sulfite in $100 \mathrm{ml}$ deionized water for $4 \mathrm{~h}$, which resulted in a solution that was approximately $0.4 \mathrm{M}$ in $\mathrm{Na}_{2} \mathrm{SeSO}_{3}$. Chemical baths of three different compositions, a), b) and c), were prepared:

a) To $25 \mathrm{ml}$ of $0.1 \mathrm{M}$ solution of potassium antimony tartrate was added with stirring $2 \mathrm{ml}$ of approx. $3.7 \mathrm{M}$ triethanolamine $(50 \%$ dilution of as supplied reagent) followed by $20 \mathrm{ml}$ of $30 \%$ ammonia (aq), $10 \mathrm{ml}$ of $0.4 \mathrm{M}$ sodium selenosulfate and the rest deionized water to take the volume to $100 \mathrm{ml}$.

b) To $1 \mathrm{~g}$ of antimony trichloride $\left(\mathrm{SbCl}_{3}\right)$ was added with stirring $37 \mathrm{ml}$ of $1 \mathrm{M}$ solution of sodium citrate - a white precipitate formed initially dissolves in an excess of the reagent. Sequential addition, with stirring, of $20 \mathrm{ml}$ of $30 \%$ ammonia (aq), $24 \mathrm{ml}$ of approximately $0.4 \mathrm{M}$ sodium selenosulfate and sufficient volume of deionized water took the volume to $100 \mathrm{ml}$.

c) To $500 \mathrm{mg}$ of antimony trichloride was added $2.5 \mathrm{ml}$ of acetone to dissolve it. This was followed by the addition of $20 \mathrm{ml}$ of $1 \mathrm{M}$ sodium citrate, $15 \mathrm{ml}$ of $30 \%$ aqueous ammonia, $10 \mathrm{ml}$ of $1 \mathrm{M}$ sodium thiosulfate, $20 \mathrm{ml}$ of 0.1 $\mathrm{M}$ sodium selenosulfate (prepared by diluting the $0.4 \mathrm{M}$ solution above) and deionized water to take the volume to $100 \mathrm{ml}$.

In all the cases the solutions were clear and devoid of any precipitate at the beginning. Clean glass substrates were introduced vertically in the bath, supported against the wall of the beaker. Baths a) and b) with the substrates were placed in a Polyscience digital temperature controlled circulation bath maintained at $300 \mathrm{~K}$ and bath (c) was placed in a refrigerator $(283 \mathrm{~K})$. The depositions were allowed to proceed for different durations ranging from 1 to $6 \mathrm{~h}$ in the case of baths a) and b) and from 3-18 $\mathrm{h}$ in the case of bath $\mathrm{c}$ ). At the end of these durations, the coated substrates were taken out of the baths, washed well with distilled water and dried by blowing hot air. Both sides of the substrates were coated with brown colored films, characteristic color of antimony selenide. The thin film deposited on the side of the substrate, which faced the wall of the beaker was chosen for characterization-the film from the other side was removed with cotton swabs moistened with dilute $\mathrm{HCl}$. The thicknesses of the films were, for bath a): $0.1 \mu \mathrm{m}(2 \mathrm{~h})-0.4 \mu \mathrm{m}(4 \mathrm{~h})$; bath b): 0.2 $\mu \mathrm{m}(1 \mathrm{~h})-0.7 \mu \mathrm{m}(5 \mathrm{~h})$ and bath $\mathrm{c}): 0.2 \mu \mathrm{m}(3 \mathrm{~h})-0.4 \mu \mathrm{m}$ (18 h). An Alfa Step 100 (Tencor Inc., CA) was utilized for the measurement of thin film thickness.

\subsection{Post-deposition treatments on the films}

The thin films of approximate thickness $0.4 \mu \mathrm{m}$ were heated to different temperatures in a vacuum oven (T-M High Vacuum Products) in a nitrogen atmosphere of 100 mTorr at $573 \mathrm{~K}$ for $1 \mathrm{~h}$ to facilitate structural and compositional modifications. To heat the films in presence of selenium, samples of size $2.5 \times 2 \mathrm{~cm}^{2}$ and weighed quantities 5 or $50 \mathrm{mg}$ of selenium powder were placed adjacent to each other in a petri dish. The latter, covered with its lid, was placed in the vacuum oven and the chamber was evacuated to a pressure of 10 mTorr and simultaneously heated to $393 \mathrm{~K}$ to eliminate any trace of moisture from the samples. Subsequently, nitrogen was introduced into the chamber to a pressure of 2000 mTorr and the oven temperature was raised to $573 \mathrm{~K}$. The heating lasted for $1800 \mathrm{~s}$.

\subsection{Characterization}

XRD patterns of the films were recorded on a Rigaku DMax X-ray diffractometer using $\mathrm{Cu}-\mathrm{K}_{\alpha}$ radiation. The elemental composition of the films was done by electron probe microanalysis in a Scanning Electron Microscope, model Carl Zeis DMS 940 A, over a sample area of approximately $300(\mu \mathrm{m})^{2}$. Optical transmittance $(T \%)$ and reflectance $(R \%)$ spectra of the films with air and a front aluminized mirror as references, respectively, were recorded on a Shimadzu UV-3101PC UV-VIS-NIR spectrophotometer. For the electrical measurements, a pair of coplanar 
silver paint electrodes was printed on the films. The photocurrent response in the samples was measured with the samples in the dark for the first $20 \mathrm{~s}$, and under an intensity of illumination of $700 \mathrm{~W} \mathrm{~m}^{-2}$ of tungstenhalogen light during the next $20 \mathrm{~s}$. During the last $20 \mathrm{~s}$ the decay of the photo-generated current was recorded. A computerized system using a Keithley 619 electrometer and a Keithley 230 programmable voltage source was used for recording the data.

\section{Results and discussion}

\subsection{Structure and composition}

The XRD patterns of the as-prepared films of $0.4 \mu \mathrm{m}$ in thickness do not show well-defined peaks. Upon annealing at $573 \mathrm{~K}$ for $1 \mathrm{~h}$ under a nitrogen atmosphere of $100 \mathrm{mTorr}$, the XRD patterns of the films recorded at room temperature show peaks which match those of $\mathrm{Sb}_{2} \mathrm{O}_{3}$ (PDF 43-1071) in intensity and $2 \theta$ positions [11], as given in Fig. 1 . In the case of film deposited from bath c), dominant peaks of $\mathrm{Sb}_{2} \mathrm{Se}_{3}$ (PDF 75-1462) [11], for example those due to diffraction from (120), (211), and (221) planes at $2 \theta$ of $16.87^{\circ}, 28.2^{\circ}$, and $31.16^{\circ}$, respectively may be identified. Since all the films appeared brownish, and not transparent as expected for $\mathrm{Sb}_{2} \mathrm{O}_{3}$, the films heated in nitrogen contain

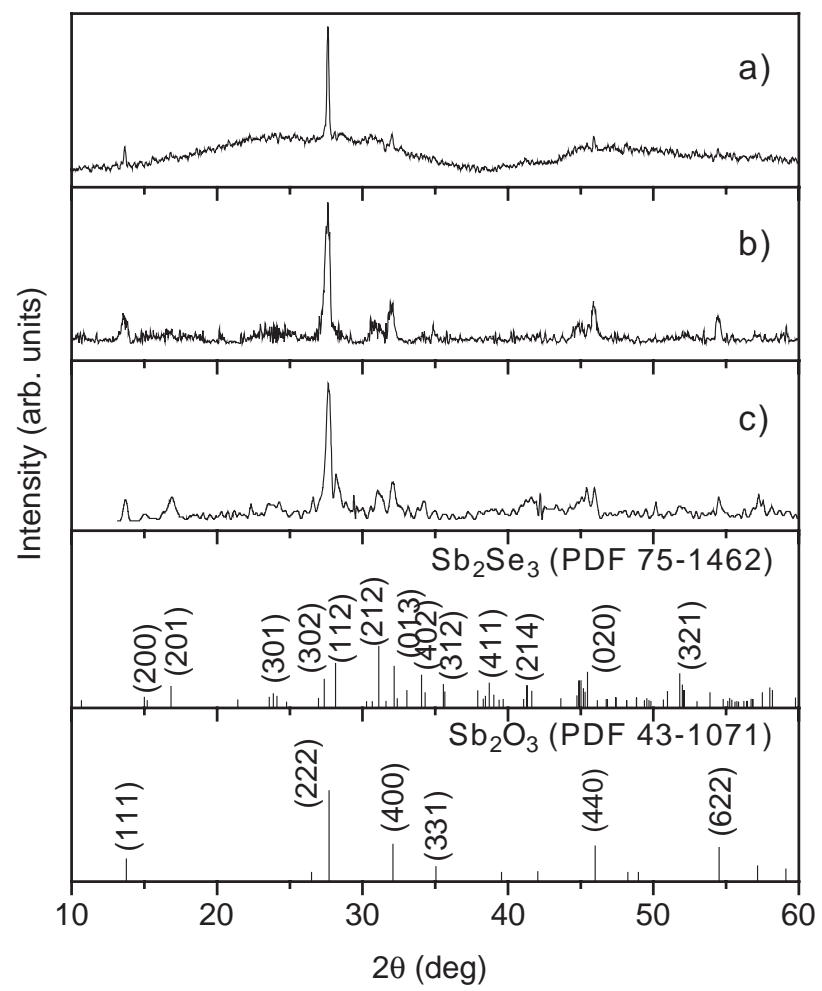

Fig. 1. XRD patterns of the films of thickness approximately $0.4 \mu \mathrm{m}$, obtained from baths a), b) and c) after they have been heated for $1 \mathrm{~h}$ at 573 $\mathrm{K}$ under nitrogen (100 mTorr). The standard patterns are given for comparison.

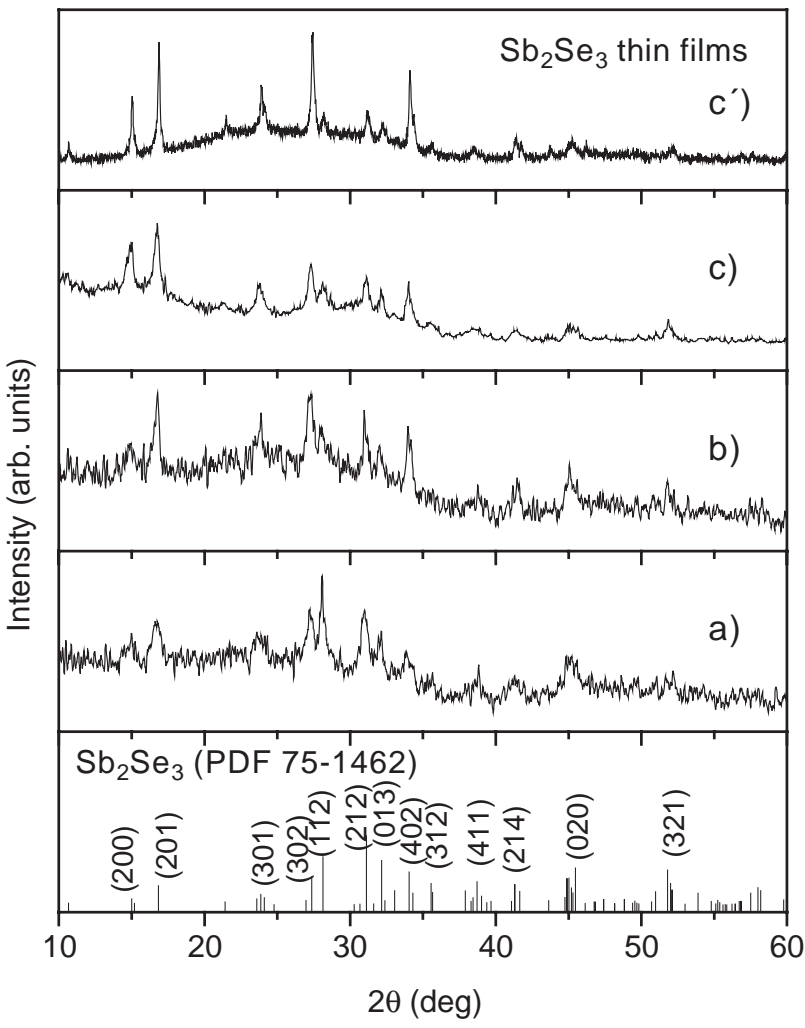

Fig. 2. XRD patterns of the films of thickness approximately $0.4 \mu \mathrm{m}$ obtained from baths a), b) and c) after they have been heated for $1800 \mathrm{~s}$ at $573 \mathrm{~K}$ in presence of Se-vapor evolved from $5 \mathrm{mg}$ of Se powder and under a nitrogen atmosphere (2000 mTorr). The pattern $\left.c^{\prime}\right)$ is recorded for the film from bath c) when heated along with $50 \mathrm{mg}$ Se powder.

crystalline phase of $\mathrm{Sb}_{2} \mathrm{O}_{3}$ and $\mathrm{Sb}_{2} \mathrm{Se}_{3}$; the latter having not transformed into crystalline state upon heating at $573 \mathrm{~K}$. This is in accordance with previously reported conclusions [12].

Composition analyses of the films, done using the electron microprobe analysis, indicated that the $\mathrm{Sb}: \mathrm{Se}$ mole ratio in the films did not comply with the value of $1: 1.5$, expected for single phase $\mathrm{Sb}_{2} \mathrm{Se}_{3}$ thin films. The $\mathrm{Sb}$ : Se ratio in the thin films prior to annealing in nitrogen were found to be: $1: 0.5$ for the films deposited from baths a) and b), and $1: 0.7$ for that obtained from bath $\mathrm{c}$ ). After the annealing in nitrogen, these values changed to approximately $1: 0.4$, in all cases, thereby suggesting a loss of selenium. These results, together with those obtained on $\mathrm{XRD}$, show that the thin films deposited from all the three baths contain $\mathrm{Sb}_{2} \mathrm{O}_{3}$, which readily transforms to crystalline phase upon annealing at $573 \mathrm{~K}$, where as the $\mathrm{Sb}_{2} \mathrm{Se}_{3}$ phase does not. The tendency of antimony to form basic oxo-salts and hydroxide in aqueous solutions is responsible for the incorporation of the oxide phase.

In the case of an $\mathrm{Sb}: \mathrm{Se}$ mole ratio of $1: 0.5$ (films from baths a) and b) observed prior to heating), the ratio of the oxide phase to selenide phase in the films is $2: 1$ and for $\mathrm{Sb}:$ Se mole ratio of 1:0.7 (films from bath $\mathrm{c}$ ), this ratio is $1: 1$. In order to convert the oxide phase to selenide $\left(\mathrm{Sb}_{2} \mathrm{O}_{3}+3 \mathrm{Se} \rightarrow \mathrm{Sb}_{2} \mathrm{Se}_{3}\right)$ and to help in the crystallization 


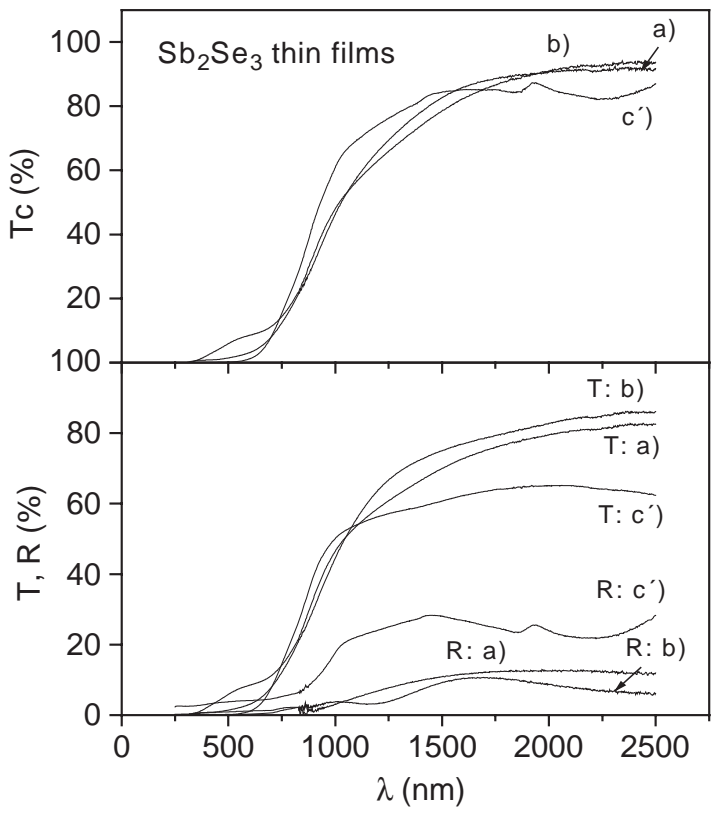

Fig. 3. Optical transmittance, reflectance, and transmittance corrected for reflectance loss ( $\left.T_{\text {corr }}\right)$ of the $\mathrm{Sb}_{2} \mathrm{Se}_{3}$ films of labels a), b) and $\left.\mathrm{c}^{\prime}\right)$ described in Fig. 2.

process, films obtained from the three baths were heated at $573 \mathrm{~K}$ for $1800 \mathrm{~s}$ in Se-vapor evolved from $5 \mathrm{mg}$ $\left(6.33 \times 10^{-5} \mathrm{~mol}\right)$ of Se-powder placed along with the samples under a nitrogen pressure of 2000 mTorr. To make an upper estimate of the selenium requirement one can assume a film thickness of $0.4 \mu \mathrm{m}$ for $\mathrm{Sb}_{2} \mathrm{O}_{3}$ (formula mass, $291.5 \mathrm{~g} / \mathrm{mol}$; mass density, $5.84 \mathrm{~g} / \mathrm{cm}^{3}$ ) and its conversion to $\mathrm{Sb}_{2} \mathrm{Se}_{3}$. Se-vapor of about $0.24 \times 10^{-5} \mathrm{~mol} \mathrm{~cm}^{-2}$ would be required over the thin film surface, which is available from the Se-source utilized.

The XRD patterns of the films obtained from the three baths and heated in the presence of the Se-vapor are given in Fig. 2. All the peaks in the patterns match well those reported for $\mathrm{Sb}_{2} \mathrm{Se}_{3}$ in PDF 75-1462. The peaks due to $\mathrm{Sb}_{2} \mathrm{O}_{3}$, seen in Fig. 1, are absent in the patterns. It was seen in the composition analyses that the $\mathrm{Sb}: \mathrm{Se}$ mole ratio approach $1: 1.5$ in the three cases. Scherrer formula may be utilized to estimate the average crystalline grain size. The values estimated for the different peaks are in the $15-30 \mathrm{~nm}$ range. It was observed that if $50 \mathrm{mg}$ of Se-powder is utilized during the heating at $573 \mathrm{~K}$ for $1800 \mathrm{~s}$, the XRD patterns become well defined, as illustrated in the XRD pattern $\mathrm{c}^{\prime}$ ) in Fig. 2 for the film obtained from bath c). The crystalline grain diameter, evaluated from the peak at $2 \theta=16.87^{\circ}$ due to diffraction from (120) planes, is about $30 \mathrm{~nm}$.

\subsection{Optical and electrical properties}

The optical transmittance $T(\%)$ and specular reflectance $R$ (\%) spectra of the films, of approximately $0.4 \mu \mathrm{m}$ in thickness obtained from baths a) and b) heated in presence of $5 \mathrm{mg}$ of selenium and that from bath c) as given in the XRD pattern $\mathrm{c}^{\prime}$ ) are given in Fig. 3. The transmittance data were corrected assuming reflection loss at the air-film

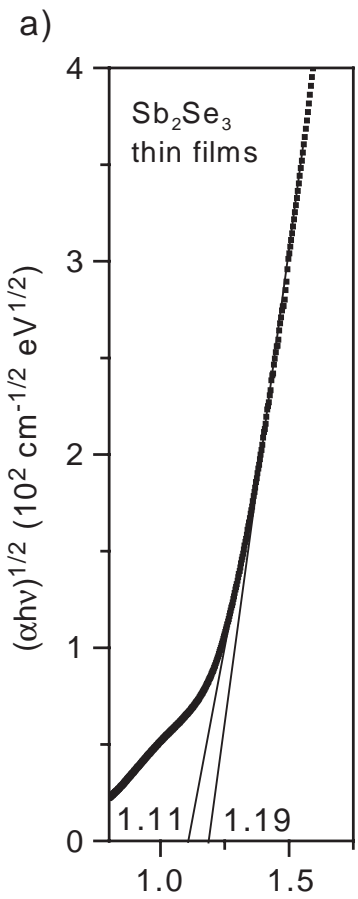

b)

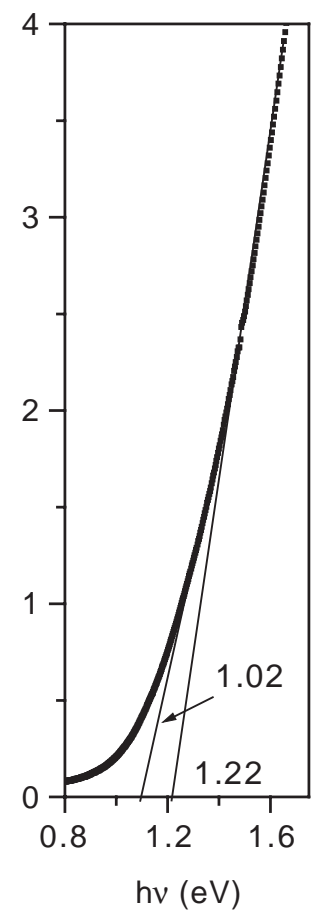

$\left.c^{\prime}\right)$

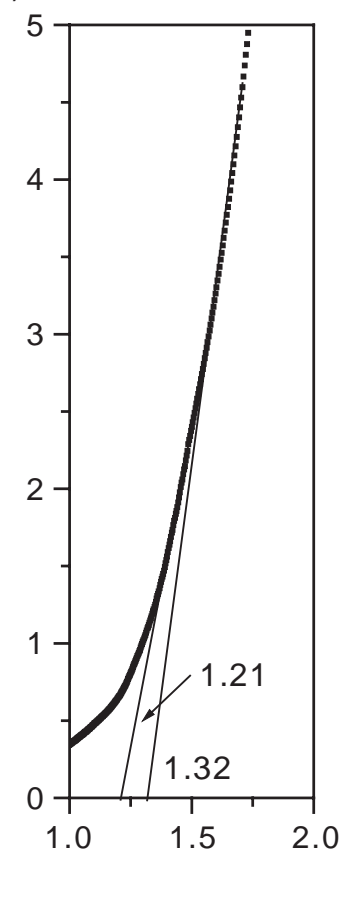

Fig. 4. Plots of the square root of the product of the optical absorption coefficient $(\alpha)$ and photon energy $h v$ against photon energy for the three films described in Fig. 3. 


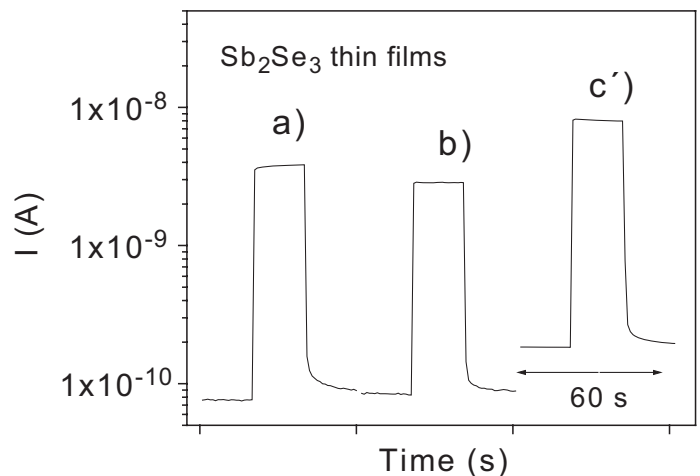

Fig. 5. Photocurrent response of $\mathrm{Sb}_{2} \mathrm{Se}_{3}$ thin films a), b) and $\mathrm{c}^{\prime}$ ) described in Figs. 2-4.

interface, $T_{\text {corr }}(\%)=100 T(\%) /[100-R(\%)]$ and are in Fig. 3 as $T(\%)$. The slow decrease of the transmittance with decrease in wavelength is characteristic of indirect band gap. The optical absorption coefficients $(\alpha)$ at different wavelengths were calculated using the formula $\alpha=(1 / d) \ln$ $100 / T_{\text {corr }}(\%)$. In Fig. 4, values of $(\alpha h v)^{1 / 2}$ are plotted against photon energy $(h v)$ for the three cases of films. Straight line regions are observed over the photon energy range 1-1.7 $\mathrm{eV}$. The smaller value indicated for the intercept in each case is the band gap energy minus the phonon energy and the larger, the sum of the two. Possible distribution of the crystalline grain diameter does not permit the exact evaluation of the band gap in thin films, but a value for the band gap in the 1.0-1.2 eV range appears to be a reasonable estimate for the crystalline $\mathrm{Sb}_{2} \mathrm{Se}_{3}$ thin films. The reported value for the optical band gap of crystalline $\mathrm{Sb}_{2} \mathrm{Se}_{3}$ is about $1.1 \mathrm{eV}$ [1].

Fig. 5 shows the photocurrent response of the crystalline $\mathrm{Sb}_{2} \mathrm{Se}_{3}$ films, obtained from the three different baths and heated in presence of selenium, the XRD patterns and optical transmittance of which were given in Figs. 2 and 3a), b), and $\mathrm{c}^{\prime}$ ). A bias, $100 \mathrm{~V}$ has been applied in each case. The electrical conductivity of the films in the dark is in the range of $(2-4) \times 10^{-8}(\Omega \mathrm{cm})^{-1}$, and upon illumination, there is an increase in the conductivity by more than an order of magnitude. The highest dark conductivity, $4 \times 10^{-8}$ $(\Omega \mathrm{cm})^{-1}$, and photoconductivity, $2 \times 10^{-6}(\Omega \mathrm{cm})^{-1}$, are observed in the case of the $\mathrm{Sb}_{2} \mathrm{Se}_{3}$ thin film obtained from bath c) and heated at $573 \mathrm{~K}$ in Se vapor.

In order to evaluate the product of mobility $(\mu)$ and free carrier life-time $(\tau)$ of photo generated charge carriers, photocurrent response for the film $c^{\prime}$ ) was recorded with monochromatic radiation of $636.5 \mathrm{~nm}$, obtained using an Oriel interference filter. The intensity of the radiation was $37 \mathrm{~W} \mathrm{~m}^{-2}$, as measured by an Eppley pyranometer. Thus, the incident photon density was $1.2 \times 10^{20}$ photons $\mathrm{m}^{-2} \mathrm{~s}^{-1}$. Fig. 3 shows that at the wavelength used, $96 \%$ of the radiation is absorbed in the thin film. Considering the film thickness, $0.4 \mu \mathrm{m}$, an estimated value for the rate of optical absorption in the bulk of the film is, $5 \times 10^{26} \mathrm{~m}^{-3} \mathrm{~s}^{-1}$. The increase in conductivity upon illumination, $3.2 \times 10^{-7}(\Omega \mathrm{cm})^{-1}$, is, $\Delta \sigma=q G \mu \tau$, and hence an estimate for the mobilitylifetime product $(\mu \tau)$ is: $3.7 \times 10^{-9} \mathrm{~cm}^{2} \mathrm{~V}^{-1}$. The best values for single crystal $\mathrm{Si}$ are around $1 \mathrm{~cm}^{-2} \mathrm{~V}^{-1}$, with a carrier life time of about $1 \mathrm{~ms}$ and electron mobility, $10^{3}$ $\mathrm{cm}^{2} \mathrm{~V}^{-1} \mathrm{~s}^{-1}$. However, in polycrystalline thin films both these parameters are many orders of magnitude lower, arising from mobility lowering due to inter-grain electric potential due to oxygen chemisorption and life time reduction due to additional recombination processes at the film surface and intergrain region. Thus, the value of the mobility-lifetime product obtained in the present case is realistic. The value may be improved further through heat treatment designed for that purpose.

\section{Conclusions}

Thin films deposited from chemical baths constituted from antimony salts and sodium selenosulfate have been found to be containing crystalline oxide phase, $\mathrm{Sb}_{2} \mathrm{O}_{3}$, along with antimony selenide, the presence of which cannot be clearly detected in XRD patterns, even after heating at 573 $\mathrm{K}$ in a nitrogen atmosphere. Composition analysis has suggested that the oxide phase might constitute half or more of the material of the thin film. Heating the films at $573 \mathrm{~K}$ in the presence of Se, evolved from Se-powder, transforms the entire film into $\mathrm{Sb}_{2} \mathrm{Se}_{3}$. These films show an indirect band gap of $1-1.2 \mathrm{eV}$. The films are photosensitive. An estimate for the mobility-lifetime product of the polycrystalline $\mathrm{Sb}_{2} \mathrm{Se}_{3}$ thin film is, $3.7 \times 10^{-9} \mathrm{~cm}^{2} \mathrm{~V}^{-1}$.

\section{Acknowledgements}

The authors are grateful to Ma. Luisa Ramon and Leticia Baños for recording the XRD patterns and to DGAPAUNAM and CONACYT-México for the financial support awarded for this work.

\section{References}

[1] O. Madelung, Semiconductors other than Group IV elements and IIIV compounds, in: R. Poerschke (Editor-in-Chief), Data in Science and Technology, Springer, Berlin, 1992, p.50.

[2] R.S. Mane, C.D. Lokhande, Mater. Chem. Phys. 65 (2000) 1.

[3] P.K. Nair, M.T.S. Nair, V.M. García, O.L. Arenas, Y. Peña, A. Castillo, I.T. Ayala, O. GomezDaza, A. Sánchez, J. Campos, H. Hu, R. Suárez, M.E. Rincón, Sol. Energy Mater. Sol. Cells 52 (1998) 313.

[4] R.N. Bhattacharya, P. Pramanik, Sol. Energy Mater. 6 (1982) 317.

[5] H.T. El-Shair, A.M. Ibrahim, E. Abd El-Wahabb, M.A. Afity, F. Abd El-Salam, Vacuum 42 (1991) 911.

[6] K.Y. Rajpure, C.H. Bhosale, Mater. Chem. Phys. 62 (2000) 169.

[7] A.P. Torane, K.Y. Rajpure, C.H. Bhosale, Mater. Chem. Phys. 61 (1999) 219.

[8] P. Pramanik, R.N. Bhattacharya, J. Solid State Chem. 44 (1982) 425.

[9] V.M. García, M.T.S. Nair, P.K. Nair, R.A. Zingaro, Semicond. Sci. Technol. 12 (1997) 645. 
[10] M. Moskovits, in: G. Soles (Ed.), Chemical Physics of Atomic and Molecular Clusters, North Holland, Amsterdam, 1990, p. 397.

[11] Powder Diffraction File, Joint Committee on Powder Diffraction Standards, International Center for Diffraction Data, Swarthmore, PA, Cards 43-1071 and 75-1462.
[12] Y. Rodríguez-Lazcano, Y. Peña, M.T.S. Nair, P.K. Nair, in: R.B. Schwarz, G. Ceder, S.A. Ringel (Eds.), Materials for Energy Storage, Generation and Transport, San Francisco, U. S. A., April 2-4, 2002, Materials Research Society Symposium Proceedings, vol. 730, 2002, p. 149. 